\title{
DEFENDING THE EPISTEMIC CONDITION ON MORAL RESPONSIBILITY
}

\author{
Martin Montminy
}

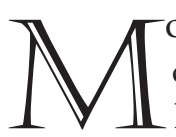

ORAL RESPONSIBILITY, tradition tells us, requires both a freedom (or control) condition and an epistemic condition. A number of authors have recently challenged this tradition, raising doubts about the epistemic condition. According to these challenges, either moral responsibility does not require such a condition in addition to a freedom condition or it does not require an epistemic condition at all. In this paper, I will examine these challenges and argue that they are unsuccessful. In other words, I will argue that moral responsibility does require a nonsuperfluous epistemic condition.

The first two challenges I will consider can be represented as a dilemma. The first horn starts with the thesis that to be blameworthy for an action, the agent must be aware of her wrongdoing. On this view, moral responsibility does involve an epistemic condition. However, some authors argue, this epistemic condition is superfluous. This is because if a person satisfies the condition for acting freely, she must know what she is doing. This entails that the epistemic condition is incorporated into the freedom condition: anyone who satisfies the freedom condition automatically satisfies the epistemic condition. The second horn of the dilemma starts with the contention that one may be blameworthy for an unwitting wrongdoing. On this view, no epistemic condition is required for moral responsibility, since a person need not know that she is doing something wrong in order to be blameworthy for her act. Hence, according to this dilemma, either moral responsibility involves no epistemic condition or the epistemic condition on moral responsibility is built into the freedom condition.

I will not take a stance on whether one may be blameworthy for an unwitting wrongdoing. But I will show that both of the challenges against the epistemic condition fail. In section 1, I will argue that although the freedom condition does incorporate some epistemic requirements, these do not include all the epistemic requirements for blameworthiness (and praiseworthiness). Then, in section 2, I will argue that a view that allows for blameworthy unwitting wrongdoings does actually involve an epistemic condition. To put it briefly, the unwitting agent is 
blameworthy for an action (or omission) only if she should know, in a sense to be explained, that that action (omission) is wrong. In section 3, I will identify more specifically what epistemic requirements the freedom condition on moral responsibility involves. This will provide further support for the traditional view that moral responsibility requires a nonsuperfluous epistemic condition.

Section 4 will be concerned with the third challenge to the epistemic condition. According to standard formulations of the quality of will view, a person is blameworthy for a wrong action just in case the action manifests ill will or a lack of goodwill. Blameworthiness does not involve any epistemic condition. I will argue that to spell out what it means for an action to manifest a problematic quality of will, one must invoke some epistemic requirements.

1. DOES THE FREEDOM CONDITION

INCORPORATE THE EPISTEMIC CONDITION?

John Fischer and Mark Ravizza advocate the traditional view according to which moral responsibility involves not only a freedom condition but also an epistemic condition. To support their position, they invoke an instance of nonculpable ignorance:

Dead Kitten: Kit is backing his car out of his garage. Kit is not under the influence, and his judgment is not addled in any way. Through no fault of his own, he is unaware that a kitten is lying right outside the garage door. Unfortunately, Kit's car is not equipped with a backup camera. Kit drives over the kitten while slowly backing his car out of his garage and kills it. ${ }^{1}$

Intuitively, Fischer and Ravizza point out, Kit is not morally responsible for killing the kitten. This is because he is unaware of the kitten's presence outside the garage, and by assumption, his ignorance is blameless. However, it seems that Kit acts freely when he is backing up the car: there is nothing wrong with his state of mind and he is in control of the car. Ignorance thus seems like an excusing condition of a different kind than lack of freedom. Cases of nonculpable ignorance such as Dead Kitten suggest that moral responsibility involves an epistemic condition in addition to a freedom condition.

Alfred Mele challenges this suggestion. ${ }^{2}$ First, he points out, the claim that Kit freely kills the kitten is highly counterintuitive. Plausibly, Kit freely holds the wheel in a certain way, freely presses the gas pedal, and freely moves the car back-

1 This story is adapted from both Fischer and Ravizza, Responsibility and Control, 12; and Mele,

"Moral Responsibility for Actions," 104.

2 Mele, "Moral Responsibility for Actions," 104. 
ward. And he is morally responsible for these actions. ${ }^{3}$ By contrast, he does not freely run over the kitten. Hence, one could argue, the reason Kit is not morally responsible for running over the kitten is that he does not perform this action freely. We can thus explain Kit's blamelessness without invoking an epistemic condition: the freedom condition suffices.

This brief explanation rests on the plausible principle that a person cannot perform an action freely unless she knows what she is doing. In other words, the freedom condition on action incorporates an epistemic requirement: a person who satisfies the freedom condition with respect to action $A$ automatically satisfies an epistemic condition with respect to $A$. The epistemic condition on moral responsibility thus seems superfluous.

Here is another way to reach the same conclusion. Mele considers the principle, which he attributes to Fischer and Ravizza, that nothing is a free action unless it is an intentional action. ${ }^{4}$ In other words, free entails intentional, or FI:

FI: Every free action is an intentional action.

If $\mathrm{FI}$ is correct, then any epistemic requirement on intentional action is also a requirement on free action. Now, as Elizabeth Anscombe contends, when we do something intentionally, we know that we are doing it. ${ }^{5}$ Anscombe's contention, combined with FI, entails that a free action is a clear-eyed action:

FK: One performs $A$ freely only if one knows that one performs $A$.

We may invoke FK to conclude that the reason Kit is not blameworthy for running over the kitten is that he did not perform this action freely. The absence of knowledge entails the absence of freedom. Kit is blameless because the freedom condition is not satisfied. Therefore, ignorance excuses because lack of freedom excuses.

Mele asks, "What epistemic requirements for being morally responsible for performing an action $A$ are not also requirements for freely performing $A$ ?" His answer is "I do not know." Like Mele, Neil Levy considers Fischer and Ravizza's

3 As Mele points out, it is a contentious matter whether moving the car backward in a certain way and killing the kitten are different actions or, according to a Davidsonian coarse-grained view, the same action under different descriptions. Like Mele, I wish to remain neutral on the individuation of actions. However, in what follows, I will use the simpler language of the fine-grained view. Translation to a Davidsonian language should be straightforward.

4 Mele, "Moral Responsibility for Actions," 106; Fischer and Ravizza, Responsibility and Control, 64 .

5 Anscombe, Intention, 13-14.

6 Mele, “Moral Responsibility for Actions," 108. 
claim that moral responsibility involves an epistemic condition that is distinct from the freedom condition:

Fischer and Ravizza, for instance focus on the control condition, rather than the epistemic condition. This is a mistake, I shall argue: the epistemic condition isn't independent of the control condition but built right into it.... Possession of the kind of control that matters in the debate, the kind of control that (allegedly) justifies attributions of moral responsibility, requires satisfaction of a demanding set of epistemic conditions. ${ }^{7}$

Levy imagines the following case:

Peanut Butter: Betty has a peanut allergy, but Grandfather does not know that. Moreover, Grandfather's ignorance is nonculpable: he was never informed that Betty is allergic to peanuts and has no reason to suspect that she suffers from this condition. At lunch, Grandfather feeds Betty peanut butter. This produces an anaphylactic reaction, and Betty must be brought to the emergency room. ${ }^{8}$

Because of his ignorance, Grandfather is not blameworthy for Betty's anaphylactic reaction. However, Levy points out, he certainly does not intentionally or freely cause that reaction. He thus lacks control over that: intuitively, he would have had control over the reaction only if he had known about Betty's allergy. Hence, once again, to account for Grandfather's blamelessness, there is no need to appeal to an epistemic condition. We can simply invoke the control (or freedom) condition on moral responsibility, which incorporates the epistemic condition.

Mele's and Levy's objections rest on a mistake, though. Grandfather freely and intentionally gives peanut butter to Betty. Given FK, this means that he knows that he is giving her peanut butter. But giving peanut butter to Betty is morally wrong, since it will (likely) produce an anaphylactic reaction in her. Why is Grandfather blameless for serving peanut butter to Betty, then? Because he does not know that giving Betty peanut butter is morally wrong. (Alternatively, the answer could be that he does not know that giving Betty peanut butter will harm her. I will come back to this point in section 4.) In other words,

7 Levy, Hard Luck, 110-11. Levy's criticism of Fischer and Ravizza is ambiguous. He may be interpreted as holding that "the" epistemic condition on moral responsibility is, as he puts it, "built right into" the freedom condition. This is how I read him here. He could also be making the weaker claim that satisfying the freedom condition "requires satisfaction of a demanding set of epistemic conditions." This weaker claim is true; however, it is an unfair objection to Fischer and Ravizza, since, as we will see in section 3, they impose several epistemic constraints on free action.

8 Levy, Hard Luck, 113. 
Grandfather is not blameworthy for serving Betty peanut butter because he does not satisfy the epistemic condition with respect to this action, even though he performs this action freely.

The point is that the epistemic condition on moral responsibility for an action concerns not only what the action is but also its moral significance. In other words, to be blameworthy for a wrongdoing $A$, a person must know not just that he is performing $A$ but also that $A$ is morally wrong. And, as we saw, satisfying the freedom (control) condition with respect to action $A$ only requires that the agent know that he is performing $A$. For this reason, the freedom (control) condition does not incorporate the epistemic condition.

Consider Dead Kitten again. Kit does not freely and intentionally kill the kitten. But he does back his car out of his garage at a certain time and in a certain manner. Call this action backing out, for short. Given the presence of the kitten, backing out is the wrong thing to do. Now, Kit backs out freely and intentionally. He is not blameworthy for backing out, since he is not aware that backing out is morally wrong. An epistemic condition that is not entailed by the freedom condition is thus needed to account for the fact that Kit is blameless for backing out.

Mele's and Levy's arguments would go through if they were restricted to actions such as wrongfully backing out or wrongfully serving peanut butter. Suppose Grandfather freely (and intentionally) wrongfully serves peanut butter to Betty. Grandfather has control over his wrongfully serving peanut butter. This, in turn, very plausibly entails that he knows that he is wrongfully serving peanut butter. Here, the freedom condition on wrongfully serving peanut butter does incorporate the epistemic condition on that action. Unfortunately, as we saw, this argument does not extend to backing out or serving peanut butter.

It is worth considering a similar argument that focuses on praiseworthiness. Paulina Sliwa contends that "moral responsibility inherits its epistemic condition from the epistemic condition on intentional action." Sliwa first points out that the success of an intentional action $A$ should not be accidental. One may intend to do $A$ and succeed, but if one's success is a matter of chance, then, intuitively, one does not do $A$ intentionally. The outcome of an intentional action, Sliwa remarks, should result from the exercise of agential control. She characterizes this control as know-how. According to Sliwa, one intentionally does A only if $A$ results from one's intention to perform $A$ and one's knowledge of how to do A. Applied to right actions, this principle entails that "intentionally doing the right thing requires both an intention to do what's right and knowledge of how to do the right thing." ${ }^{.10}$ Sliwa then turns to praiseworthiness. She contends that

9 Sliwa, "On Knowing What's Right and Being Responsible for It," 127.

10 Sliwa, "On Knowing What's Right and Being Responsible for It," 131. 
praiseworthiness for a right action requires intentionally doing the right thing. Therefore, moral knowledge is a necessary condition on praiseworthiness for a right action because it is a necessary condition on intentionally acting rightly.

Let us grant Sliwa's conclusion that one is praiseworthy for an action only if one knows that one is acting rightly. Does this conclusion entail that praiseworthiness inherits its epistemic condition from the epistemic condition on intentional action? No. Suppose Zara donates a certain amount of money to a charity. Call Zara's action donating, for short. According to Sliwa's condition on praiseworthiness, Zara is praiseworthy for her action only if she intentionally does the right thing. And given Sliwa's condition on intentional action, this entails that Zara is praiseworthy for her action only if she knows that she is acting rightly. This means that Zara is praiseworthy for donating only if she knows that donating is the right thing to do or, as I will write, only if she knows that she is donating rightly. But intentionally donating is not the same as intentionally donating rightly. Only the latter requires knowledge that donating is the right thing to do. Hence, while the epistemic condition on praiseworthiness for donating requires that Zara know that she is donating rightly, the epistemic condition on intentionally donating only requires that Zara know that she is donating. This means that praiseworthiness for donating does not inherit its epistemic condition from the epistemic condition on intentionally donating. Sliwa's thesis is true only of actions such as donating rightly: praiseworthiness for donating rightly does inherit its epistemic condition from the epistemic condition on intentionally donating rightly.

Simply put, my argument is as follows. Not every right action is transparently right, and not every wrong action is transparently wrong. Plausibly, as we have seen, a person who freely and intentionally does $A$ knows that she is doing $A$. But this does not entail that she knows whether $A$ is right or wrong. This means that the epistemic requirements for being morally responsible for doing $A$ are not also requirements for freely and intentionally doing $A$.

So far, I have assumed that the epistemic condition on blameworthiness (praiseworthiness) for an action requires knowledge that the action is wrong (right). This assumption is contentious. In the next section, I will consider a way in which the condition may be weakened with respect to blameworthiness. In section 4, I will mention an alternative way to construe the content of the knowledge attitude. But I should also point out that it is not obvious that the attitude involved in the epistemic condition should be knowledge. Some have argued for other attitudes, such as true belief, justified belief, or mere belief. ${ }^{11}$ In the rest of the essay, I will talk as if knowledge is the attitude invoked by the epistemic condition, but substituting another attitude for knowledge would not affect my arguments.

11 See Rudy-Hiller, “The Epistemic Condition for Moral Responsibility, for a useful overview. 


\section{UNWITTING WRONGDOINGS}

According to the epistemic condition discussed in the previous section, a person is blameworthy for a wrong action $A$ only if she knows that $A$ is wrong. Consider first a flawed counterexample to this condition.

Asleep at the Wheel: Shasta is very eager to reach her destination and has been driving her car for over ten hours. Her eyelids are droopy and her head starts to nod. She ignores these symptoms and keeps driving. Soon, she falls asleep and collides with another car.

Clearly, when she is asleep, Shasta has no awareness of the other car. However, intuitively, she is to blame for the collision.

Asleep at the Wheel does not threaten the epistemic condition, though. This is because Shasta is derivatively (or indirectly) blameworthy for colliding with the other vehicle. Her blameworthiness for the collision derives from her direct blameworthiness for driving while feeling sleepy. The epistemic condition, it should be clear, is meant to be a condition on direct moral responsibility and blameworthiness. Plausibly, Shasta is directly blameworthy for driving while feeling sleepy. Moreover, she plausibly satisfies the epistemic condition regarding that act, since she is plausibly aware that it is wrong. Hence, Asleep at the Wheel does not threaten the epistemic condition.

Here is a case, imagined by George Sher, that more clearly challenges the epistemic condition. ${ }^{12}$

Hot Dog: Alessandra is picking up her children at their elementary school. Although it is hot, she leaves Sheba, the family dog, in the car while she goes to gather her children. Since the pickup is always quick, this has never been a problem. This time, however, Alessandra has several conversations with other parents and completely forgets about Sheba. When she and her children finally come back to the parking lot, they find Sheba unconscious from heat prostration.

According to Sher, Alessandra is morally responsible (and blameworthy) for leaving Sheba in the hot car for so long. More specifically, Alessandra is directly blameworthy for that omission. (From now on, when the context makes it clear, I will omit "directly" before "blameworthy.") Hot Dog is an instance of a blame- 
worthy unwitting omission: Alessandra does not knowingly leave Sheba in the hot car. Hence, she is blameworthy for doing something she does not know is wrong.

Let us grant Sher's assessment, and see what it entails regarding the epistemic condition. As Sher points out, Hot Dog is a counterexample to the searchlight view, a view according to which a person is responsible only for the features of her acts that she is aware of. ${ }^{13}$ However, Hot Dog does not show that responsibility involves no epistemic requirement. Discussions of the epistemic condition often construe this condition as disjunctive: a person is blameworthy for a wrongdoing only if she knows or should know (or is reasonably expected to know) that she is doing the wrong thing. ${ }^{14}$

There are several ways to specify what "should know" means. For example, it can mean that the person was in a position, prior to her action, to investigate the matter. A paramedic who is unable to use a defibrillator when attending a patient in cardiac arrest is blameworthy for her inaction. This is because she should know how to operate the device, given her training. If her ignorance is due to her inattention in class or her failure to study, then she is derivatively blameworthy for her incompetent treatment of the patient. Since our interest is in direct blameworthiness, I will set aside this particular understanding of "should know."

Hot Dog provides us with another way to understand "should know." Alessandra should know that Sheba is at risk of heat prostration, given her evidence (the high temperature, the fact that Sheba is in the car, and so on) and her cognitive capacities. Alessandra is at fault because, while she is talking with other parents, she is capable of remembering Sheba's situation. Her forgetting, as Sher puts it, is substandard: given her cognitive capacities, Alessandra should have remembered. ${ }^{15}$ In other words, Alessandra's forgetting is a type of underperformance: she does not perform according to her cognitive abilities. ${ }^{16}$

More recently, Sher has proposed a statement of the epistemic condition that accommodates his case: "When a morally ignorant wrongdoer satisfies all the non-epistemic conditions for blameworthiness, he is blameworthy for acting wrongly if, but only if, he was at least in a position to recognize that his act was wrong when he performed it." ${ }^{17}$ Clearly, Sher's epistemic condition is not automatically satisfied when the freedom condition is. We may assume that Alessan-

Sher, Who Knew? 6.

See, among others, Fischer and Ravizza, Responsibility and Control, 12; Ginet, "The Epistemic Requirements for Moral Responsibility”; and Vargas, Building Better Beings, 201-2.

Sher, Who Knew? 110.

Montminy, "Doing One's Reasonable Best"; Raz, "Being in the World”; Michael Smith, "Rational Capacities."

17 Sher, "Blame and Moral Ignorance," 101. 
dra freely stays in the school to talk to other parents for several minutes. She is blameworthy for this action, because she is in a position to know that it is wrong.

A possible response is worth considering. One may point out that it would not be unreasonable to broaden the freedom condition similarly to the way in which we just broadened the epistemic condition. In a sense, Alessandra was free to come back to the car more quickly. She had that freedom: she just failed to exercise it appropriately. As Randolph Clarke remarks,

Even if, in a case of unwitting omission, the agent doesn't exercise control with respect to whether she performs the omitted action, she might have control over whether she performs that action, for she might be able to exercise, and have the opportunity to exercise, such control-she might be able, and have the opportunity, to perform the action in question. She might thus be free to perform it, even if there's nothing that is her omission and is an exercise of freedom. ${ }^{18}$

According to the broader freedom condition, an action is free either if the agent performed it freely or if she was free to perform it. Arguably, Alessandra was free to come back to her car in time. Moreover, although Alessandra did not intentionally leave the dog in the hot car, she was able to intentionally come back to the car. And if she had intentionally come back to her car, she would have known that she was going back to her car.

The broader freedom condition thus incorporates an epistemic condition. Does it incorporate the epistemic condition on blameworthiness? No. If Alessandra had freely come back to her car, she would have known that she was going back to her car. But Alessandra's capacity to form this knowledge does not give her knowledge of the moral significance of either her current or her alternative action. Generally speaking, according to the broader freedom condition, a person is blameworthy for not doing $A$ only if she was free to do $A$. Based on plausible assumptions, this means that a person is blameworthy for not doing $A$ only if she had the capacity to know, while doing $A$, that she was doing $A$. One may possess this capacity without satisfying the epistemic condition on blameworthiness. According to the latter, the person should be able to know, through the exercise of her cognitive abilities, that not doing $A$ is wrong. Hence, one may satisfy the broader freedom condition with respect to an omission without satisfying the epistemic condition on blameworthiness for that omission.

Following Clarke, let us call the view presented in this section the ability view 
(hereafter Av) ${ }^{19}$ A morally responsible person has cognitive and volitional abilities, and according to AV, she is blameworthy for a wrongdoing $A$ only if her doing $A$ results from a substandard failure to exercise these abilities. (Recall that a failure is substandard when the agent fails to exercise her own abilities successfully. In other words, the agent fails to perform according to her abilities.) According to Av, blameworthiness has two sources: it may be due to a substandard failure to exercise one's motivational or volitional abilities to do the right thing (clear-eyed wrongdoing); it may also be due to a substandard failure to recognize what the right thing to do is (unwitting wrongdoing).

\section{THE EPISTEMIC REQUIREMENTS ON FREEDOM}

As we saw in section 1, both Mele's and Levy's arguments target Fischer and Ravizza's account of moral responsibility. Mele writes, "According to Fischer and Ravizza, what epistemic requirements for being morally responsible for performing an action $A$ are not also requirements for freely performing $A$ ? My answer at this point is straightforward, even if it is unsatisfying: I do not know." ${ }^{20}$ And Levy contends that Fischer and Ravizza mistakenly attempt to treat the freedom condition independently of the epistemic condition. Now, both Mele and Levy correctly point out that freedom does incorporate some epistemic requirements. In this section, I will try to specify this point further, focusing on Fischer and Ravizza's account of the freedom condition. This will provide further support for the claim that a nonsuperfluous epistemic condition on moral responsibility is needed.

Fischer and Ravizza characterize the freedom condition on moral responsibility as guidance control. They identify guidance control over an action $A$ with $A$ 's resulting from the agent's own reasons-responsiveness. ${ }^{21}$ Reasons-responsiveness consists in two mechanisms: a reasons-receptive mechanism, which is in charge of recognizing the reasons for an action, and a reasons-reactive mechanism, whose role is to act on those reasons in a given circumstance. Reasons-receptivity is thus a kind of cognitive ability, and reasons-reactivity, a kind of volitional ability. ${ }^{22}$

19 Clarke, "Blameworthiness and Unwitting Omissions."

20 Mele, "Moral Responsibility for Actions," 108.

21 Fischer and Ravizza, Responsibility and Control, chs. 2-3. To exclude cases of manipulation, Fischer and Ravizza insist that the mechanisms should be the agent's own, and then they analyze mechanism ownership in terms of taking responsibility. I will not explore this part of their account.

22 I will often talk of people's rather than mechanisms' reasons-responsiveness. Fischer and Ravizza's focus on mechanisms is motivated by considerations about Frankfurt-style cases. This will not be a concern here, as I will assume that Frankfurt devices are always absent. 
According to Fischer and Ravizza, a person performs an action $A$ freely on a given occasion only if $A$ results from reasons-responsive mechanisms. These mechanisms should be such that in a reasonable proportion of nearby possible scenarios in which there are sufficient reasons to do otherwise, the person's reasons-receptive mechanism recognizes these reasons and the person's reasons-reactive mechanism chooses otherwise based on these reasons. (Given our purposes, it is not crucial to specify the threshold marked by "reasonable proportion.") But this is not all. To be free, $A$ must be produced in the right way by the mechanisms. This means that the agent must act based on a reason $R$. Four points are worth emphasizing. First, $R$ need not be a sufficient, or even a good, reason for $A$. To perform $A$ freely, the agent must have the capacity to recognize sufficient reasons, but she may be mistaken that $R$ is sufficient for $A$ on this particular occasion. For example, a parent may freely spank a child to discipline him based on a mistaken belief that it is the right thing to do. Second, $R$ need not be a moral reason: acting freely does not require acting based on moral reasons. A free action may be based on a person's (nonmoral) values. For example, one can freely eat a piece of cake because one enjoys the taste. Third, one may do $A$ based on $R$, even though one takes $R^{*}$ to be a sufficient reason for an alternative course of action $B$. To freely do $A$, an agent must have the capacity to do otherwise based on sufficient reasons to do otherwise, but the agent need not have a perfect record. Clear-eyed wrongdoings illustrate this point: even though the agent knows that there is a sufficient moral reason to do $B$ rather than $A$ because $B$ is morally right and $A$ is not, she may still do $A$ freely. Fourth, according to principle FK of section 1, to do $A$ freely, the agent must know that she is doing $A$.

The freedom condition with respect to action $A$ thus incorporates some epistemic requirements, but it does not include the requirement that the agent know or should know about the moral significance of $A$. Hence, moral responsibility for $A$ involves an epistemic condition that goes beyond what the freedom condition requires. I will illustrate this point with some examples, starting with a praiseworthy action. Suppose Meili rescues a trapped child from a burning house. Call Meili's action rescuing, for short. To rescue freely, Meili must satisfy different epistemic requirements: (1) she must have the ability to recognize sufficient reasons to do otherwise in a reasonable proportion of nearby possible scenarios, (2) she must consider (explicitly or implicitly) that there is a reason for rescuing, and (3) she must know that she is rescuing. Note that 2 does not require Meili's reason for rescuing to be moral. She may rescue for a monetary reward, for example. This would not make her action unfree. Clearly, 1-3 do not require Meili to know that rescuing is the right thing to do. But as we saw in section 1 , to be praiseworthy for her action, Meili must know that rescuing is right or 
recognize that there is a morally sufficient reason for rescuing. Therefore, praiseworthiness for rescuing involves an epistemic condition that is additional to the freedom condition.

The conditions on blameworthiness for a wrongdoing are a little more complicated, because we may allow for blameworthy unwitting wrongdoings in addition to blameworthy clear-eyed wrongdoings. Let us start with an example of the latter. Suppose a hired assassin kills an innocent person for money. Call this action killing, for short. In this case, the assassin freely kills while knowing that the right course of action would be not killing. In other words, he recognizes that there is sufficient moral reason for not killing, but he nevertheless kills. The assassin kills not based on the recognition of sufficient moral reasons, but based on the recognition of some selfish reason-that is, his desire for money. Clearly, this fact does not entail that his action is not free. To kill freely, the assassin must satisfy the following epistemic requirements: (1) he must have the ability to recognize sufficient reasons to do otherwise in a reasonable proportion of nearby possible scenarios, (2) he must consider that there is a reason for killing, and (3) he must know that he is killing. But the epistemic condition on blameworthiness for killing requires that the assassin recognize some sufficient moral reason for not killing or that he recognize that killing is wrong. Once again, the freedom condition on blameworthiness does not incorporate the epistemic condition.

Let us turn to Hot Dog, a case of unwitting wrongdoing. Let us call chatting Alessandra's free action of chatting for a significant period of time with other parents while in the school building. In this case, chatting is the wrong thing to do: Alessandra should go back to the parking lot and release Sheba from the hot car (hereafter going back). Alessandra does not realize that chatting is the wrong thing to do and that there is a sufficient moral reason for going back. However, we may suppose that Alessandra chats based on the recognition of some reason for chatting, say, to cultivate her friendly rapport with other parents. To chat freely, Alessandra must satisfy the following epistemic requirements: (1) Alessandra must have the ability to recognize sufficient reasons to do otherwise in a reasonable proportion of nearby possible scenarios, (2) she must consider that there is a reason for chatting, and (3) she must know that she is chatting. Now, recall that according to $\mathrm{AV}$, to be blameworthy for chatting (and for not going back), Alessandra must have the ability to recognize that there is a sufficient moral reason for not chatting (and a sufficient moral reason for going back). Clearly, the fact that Alessandra satisfies 1-3 does not entail that she satisfies this epistemic condition on blameworthiness. Hence, the epistemic requirements entailed by the freedom condition do not incorporate the epistemic condition on blameworthiness in this case either. 
Now, I need to consider one complication. Toward the end of their discussion, Fischer and Ravizza strengthen their account of guidance control by requiring that the agent be receptive not just to reasons in general but also to moral reasons. ${ }^{23}$ This, they point out, allows them to hold that intelligent animals, young children, or psychopaths who are unable to appreciate moral reasons are not morally responsible for their actions. ${ }^{24}$ I should first note that although receptivity to moral reasons is very plausibly a condition on moral responsibility, it does not strike me as a plausible condition on freedom. A person who is unable to grasp moral reasons should not be held morally responsible for his actions; however, such a person could still act freely it seems. I would instead hold that the capacity to grasp moral reasons is an epistemic condition on moral responsibility that is additional to the epistemic requirements entailed by freedom. At any rate, let us assume that Fischer and Ravizza are right and that the freedom condition on moral responsibility does require the capacity to recognize moral reasons. One may possess this capacity without satisfying the epistemic condition on blameworthiness. Consider Alessandra again. Fischer and Ravizza's additional epistemic requirement entails that she cannot be blameworthy for anything unless she has the ability to recognize moral reasons. We can safely assume that Alessandra, being a normal human adult, does meet this epistemic requirement. But this does not entail that she possesses the ability to recognize that chatting is the wrong thing to do in her circumstances and that she should go back instead. Hence, an epistemic condition is still required in addition to Fischer and Ravizza's strengthened freedom condition.

\section{QUALITY OF WILL}

Let us now consider the third challenge against the epistemic condition on mor-

23 Fischer and Ravizza, Responsibility and Control, 76-81.

24 Surprisingly, Fischer and Ravizza claim that moral responsibility does not require that the agent be reactive to moral reasons (Responsibility and Control, 79). According to them, a person may be morally responsible for his actions even though he is completely unable to translate moral reasons into action. Two remarks. First, Fischer and Ravizza's position is implausible: it seems that a person who is unable to react to moral reasons has an excuse for his wrongdoings. Second, Fischer and Ravizza's position appears to contradict a principle they invoke in defense of their contention that weak reactivity to reasons is all the reactivity required for moral responsibility. According to what they call a fundamental intuition, reactivity is "all of a piece." By that, they mean that if an agent can react to some incentive to do other than he actually does, then he can react to any incentive to do otherwise (73). Hence, according to Fischer and Ravizza's fundamental intuition, any person with weak reactivity should be able to translate moral reasons into action. (Thanks to an anonymous reviewer for pointing this out.) 
al responsibility. According to the quality of will view (hereafter $\mathrm{QW}$ ), a person is blameworthy for a wrong action just in case the action manifests ill will or a lack of goodwill. A person who hurts others out of hatred or sadism manifests ill will. Culpability may also be due to a lack of goodwill, or moral indifference. Someone who steals or lies for purely selfish reasons manifests moral indifference.

QW is a family of views. Some of its proponents reject the possibility of blameworthy unwitting wrongdoings. Michael McKenna, an advocate of $\mathrm{QW}$, suggests that a person is blameworthy for an action only if she knows that her action is wrong. ${ }^{25}$ On this version of $\mathrm{QW}$, only clear-eyed wrongdoings may be blameworthy. This brand of Qw thus explicitly admits an epistemic condition. Given that my interest is in challenges to this condition, I will disregard this version of $\mathrm{QW}$ and focus solely on versions of $\mathrm{QW}$ that allow for blameworthy unwitting wrongdoing. ${ }^{26}$

When a person is blameworthy for a clear-eyed wrongdoing, she manifests a bad quality of will roughly as follows. The person has problematic desires (or pro-attitudes) — for example, a selfish desire or a desire for the wrong. Since the person's problematic desires are stronger than her desire for the right, they bring about (in a nondeviant way) the wrongdoing. The person's action thus manifests a bad quality of will. Suppose that Fernanda detests her colleague Violeta. Because of that, her desire to hurt Violeta is stronger than her concern for Violeta's welfare. During lunch break, Fernanda's problematic desire causes her to cruelly tease Violeta. Fernanda is blameworthy for her action because it manifests ill will toward Violeta.

Things are very different in cases of blameworthy unwitting wrongdoings. In such cases, the wrongdoer either harbors a certain dose of ill will or lacks the proper amount of goodwill. This problematic quality of will somehow affects his ability to acquire the relevant knowledge at the right time. This, in turn, leads him to unwittingly do the wrong thing. Nomy Arpaly and Timothy Schroeder, two proponents of QW, discuss the case of Victor, a professor who, unbeknownst to him, is prejudiced against students who wear their baseball caps backward. ${ }^{27}$ While grading essays, Victor unknowingly gives a student an unfair grade because he remembers the student as wearing his baseball caps backward. Victor is

McKenna, Conversation and Responsibility, 15, 61.

See, among others, Arpaly, Unprincipled Virtue, ch. 3; Arpaly and Schroeder, In Praise of Desire; Björnsson, "Explaining (Away) the Epistemic Condition on Moral Responsibility"; Talbert, "Akrasia, Awareness, and Blameworthiness"; and Talbert, "Omission and Attribution Error."

Arpaly and Schroeder, In Praise of Desire, 238. 
blameworthy for giving the student an unfair grade because his action manifests ill will toward the student.

It is worth noting that for this kind of blameworthy unwitting wrongdoing to occur, the agent's problematic desires need not be stronger than his desire for the good. It may well be that if he came to realize that the grade he gave to the student is unfair (perhaps by comparing his essay to another of similar quality to which he gave a better grade), Victor would immediately adjust his grade, because his goodwill toward the student is stronger than his ill will toward him.

This shows that the process by which a person may manifest a bad quality of will in an unwitting wrongdoing is very different from the process by which he may manifest ill will in a clear-eyed wrongdoing. What the two instances of "manifesting" a bad quality of will have in common is that the person's problematic will is a cause of the person's wrongdoing. Plausibly, in both cases, the causal chain from problematic will to wrongdoing ought to be nondeviant. But what makes nondeviant a causal process from an objectionable desire to a clear-eyed wrongdoing has probably very little in common with what makes nondeviant a causal process from an objectionable desire to a failure to form the appropriate cognitive state at the right time.

To specify further what manifesting a problematic will amounts to in the two types of cases, we must invoke an epistemic condition. ${ }^{28}$ I will now argue that $\mathrm{QW}$, like $\mathrm{AV}$, is committed to a disjunctive epistemic condition on blameworthiness: a person is blameworthy for a wrongdoing only if she knows or should know that she is doing the wrong thing. As we will see, the key difference between QW and AV concerns how to construe "should know."

Consider QW's treatment of Hot Dog. According to QW, Alessandra is to blame for leaving Sheba in the hot car only if her forgetting is due to ill will or a lack of goodwill. Otherwise, her omission would not manifest a bad quality of will. QW thus rejects Av's epistemic condition, according to which a person is to blame for an unwitting wrongdoing if, given her abilities, she was in a position to recognize that her act was wrong when she performed it. Against this view, Matthew Talbert, a proponent of QW, writes: "Blame might be an apt response if we filled in the details so that it was clear that Alessandra's forgetting stemmed from faulty concern for Sheba's welfare, but if the explanation for Alessandra's behavior doesn't make reference to something like this, then I don't see how the morally offended responses involved in blame will have much purchase." ${ }^{29}$ presented in the previous section. See, for instance, Arpaly, Unprincipled Virtue, ch. 4.

29 Talbert, "Akrasia, Awareness, and Blameworthiness," 57. For a similar point, see Björnsson, "Explaining (Away) the Epistemic Condition on Moral Responsibility." 
Suppose that Alessandra forgot about Sheba because of her lack of concern for her. Her forgetting is thus causally explained by her objectionable quality of will. This means that if she had had an appropriate degree of concern for her dog, Alessandra would have remembered her. Therefore, Alessandra is to blame for her omission, because she should have known that she was doing something wrong, in the sense that if she had had an adequate quality of will, she would have known that. ${ }^{30}$

This epistemic condition can be further supported by considering a slightly different version of the story, which I will call Hot Dog*. In this version, while in the school building, Alessandra encounters a series of extremely stressful events such as an altercation between parents, a sick schoolchild treated by a nurse, and a conversation about a bomb threat that occurred earlier in the day. In Hot Dog*, Alessandra is not to blame for leaving Sheba in the car, even if her concern for Sheba's welfare is faulty. This is because regardless of the quality of her will, she would have forgotten about Sheba, given her exceptionally stressful circumstances. ${ }^{31}$ According to QW, a blameworthy person's problematic will must be a difference maker: Alessandra's lack of concern for Sheba must causally explain her forgetting. QW thus involves the following epistemic condition: a person is blameworthy for an unwitting wrongdoing only if she would know that she is doing the wrong thing if she had an appropriate quality of will.

At this point, it is worth mentioning an area of contention among proponents of QW. Michael Smith distinguishes between a de re and a de dicto desire for the right. ${ }^{32}$ Desiring the right de re (that is, desiring to do what is actually right) is not the same as desiring the right de dicto (that is, desiring to do what is right whatever that turns out to be). A person with goodwill, Smith insists, should care about equality, justice, and the well-being of others. A concern for the right as such does not make a person good; it is, as Smith puts it, a form of fetishism. Nomy Arpaly, Timothy Schroeder, and Julia Markovits concur with this position. ${ }^{33}$ Zoë Johnson King and Paulina Sliwa favor a de dicto condition

Here, I am employing a simple counterfactual analysis of causation à la Lewis, "Causation": Alessandra's bad quality of will caused her forgetting just in case had she had an adequate quality of will, she would have remembered. This simple analysis would clearly need to be refined to accommodate cases of overdetermination, preemption, and the like; however, it will suffice for our purposes.

31 Both Björnsson and Talbert acknowledge this point. See Björnsson, "Explaining (Away) the Epistemic Condition on Moral Responsibility," 153; Talbert, "Omission and Attribution Error," 23-24. Michael Smith, The Moral Problem, 73-76.

33 Arpaly and Schroeder, In Praise of Desire, 164-67; Markovitz, "Acting for the Right Reasons," 218-19. 
on goodwill. ${ }^{34}$ This debate is relevant to the content of the attitude invoked in the epistemic condition. Blameworthiness for an unwitting wrongdoing $A$ may require that a person with an adequate quality of will would know that $A$ is wrong (de dicto). This is how I have characterized the epistemic condition so far. But this condition could instead require that a person with an adequate quality of will would know that $A$ has such-and-such wrong-making features ( $d e r e$ ). In Hot Dog, the condition would hold that if she had goodwill, Alessandra would know that her leaving Sheba in the hot car is harming her. Although I will continue to interpret the epistemic condition as de dicto, my discussion is meant to be neutral between the two readings.

QW's treatment of Peanut Butter would also invoke the epistemic condition I just described. Grandfather does not know that feeding peanut butter to Betty is wrong. He is blameworthy for serving peanut butter to Betty only if he should know that this is wrong. According to QW, Grandfather should know about the wrongness of feeding peanut butter to Betty just in case he would know that feeding peanut butter to Betty is wrong if he had an appropriate quality of will. If Grandfather's ignorance is due to an inadequate degree of concern for Betty, then he is blameworthy for his action. In such a case, he should know that his action is wrong. But in presenting the case, we have assumed that Grandfather was not at fault for his ignorance: this means that regardless of his quality of will, it would have been impossible for him to know about Betty's allergy.

Now, it would be useful to provide an account of blameworthiness that is neutral between $\mathrm{AV}$ and $\mathrm{QW}$. Both views admit two types of blameworthy actions: clear-eyed wrongdoings and unwitting wrongdoings. A person is blameworthy for a clear-eyed wrongdoing only if her failure to refrain from doing the wrong thing is substandard. A person is blameworthy for an unwitting wrongdoing only if her ignorance, or failure to recognize the wrongness of her action, is substandard. AV and $\mathrm{QW}$ agree on both of these conditions but propose different analyses of what counts as substandard. For AV, a person's cognitive and volitional abilities set the standard: a substandard failure is one that the agent had the ability and opportunity to avoid. An agent fails in a substandard way when she fails to perform according to her abilities. For Qw, the standard is set by an appropriate quality of will: a substandard failure is one that the agent would have avoided if she had had an appropriate quality of will. An agent fails in a substandard way when she fails because of a problematic quality of will. 


\section{CONCLUSION}

A person cannot freely perform action $A$ without satisfying some epistemic requirements. Plausibly, for example, to freely do $A$, a person must know that she is doing $A$. However, as I have shown, the epistemic condition on moral responsibility for $A$ goes beyond the epistemic requirements for freely doing $A$. To be praiseworthy for a right action $A$, a person must know not just that she is doing $A$ but also that $A$ is morally right. And according to the strict view that only cleareyed wrongdoings may be blameworthy, the epistemic condition on blameworthiness for a wrong action $A$ requires not simply that the agent know that she is doing $A$ but that she know that $A$ is morally wrong. As we saw, some views adopt a looser epistemic condition according to which a person is blameworthy for a wrong action $A$ only if she knows or should know that $A$ is morally wrong. I examined two ways to analyze the locution "should know." According to AV, a person should know that $A$ is wrong just in case she has the ability and opportunity to form that knowledge. According to $\mathrm{QW}$, a person should know that $A$ is wrong just in case she would form that knowledge if she had an adequate quality of will. Although they propose slightly different analyses of "should know," both AV and QW clearly impose an epistemic condition on moral responsibility. Challenges to this condition have thus proven unsuccessful. ${ }^{35}$

\section{University of Oklahoma montminy@ou.edu}

\section{REFERENCES}

Amaya, Santiago. "Slips." Noûs 47, no. 3 (September 2013): 559-76.

Anscombe, Elizabeth. Intention. Oxford: Blackwell, 1957.

Arpaly, Nomy. Unprincipled Virtue: An Inquiry into Moral Agency. Oxford: Oxford University Press, 2003.

Arpaly, Nomy, and Timothy Schroeder. In Praise of Desire. Oxford: Oxford University Press, 2014.

Björnsson, Gunnar. "Explaining (Away) the Epistemic Condition on Moral Responsibility." In Robichaud and Wieland, Responsibility, 146-62. Oxford: Oxford University Press, 2017.

Clarke, Randolph. "Blameworthiness and Unwitting Omissions." In The Ethics 
and Law of Omissions, edited by Dana Kay Nelkin and Samuel C. Rickless, 63-83. Oxford: Oxford University Press, 2017.

- . "Ignorance, Revision, and Commonsense." In Robichaud and Wieland, Responsibility, 233-51. Oxford: Oxford University Press, 2017.

- Omissions: Agency, Metaphysics, and Responsibility. Oxford: Oxford University Press, 2014.

Fischer, John Martin, and Mark Ravizza. Responsibility and Control: A Theory of Moral Responsibility. Cambridge: Cambridge University Press, 1998.

Ginet, Carl. “The Epistemic Requirements for Moral Responsibility.” Philosophical Perspectives 14, Action and Freedom (2000): 267-77.

Harman, Elizabeth. “Does Moral Ignorance Exculpate?” Ratio 24, no. 4 (December 2011): 443-68.

Johnson King, Zoë. "Accidentally Doing the Right Thing." Philosophy and Phenomenological Research 100, no. 1 (January 2020): 186-206.

Levy, Neil. Hard Luck: How Luck Undermines Free Will and Moral Responsibility. Oxford: Oxford University Press, 2011.

Lewis, David. "Causation." Journal of Philosophy 70, no. 17 (October 1973): 55667.

Markovits, Julia. "Acting for the Right Reasons." Philosophical Review 119, no. 2 (April 2010): 201-42.

McKenna, Michael. Conversation and Responsibility. Oxford: Oxford University Press, 2012.

Mele, Alfred. "Moral Responsibility for Actions: Epistemic and Freedom Conditions." Philosophical Explorations 13, no. 2 (2010): 101-11.

Montminy, Martin. "Doing One's Reasonable Best: What Moral Responsibility Requires." Journal of the American Philosophical Association 2, no. 1 (Spring 2016): 55-73.

Nelkin, Dana K. Making Sense of Freedom and Responsibility. Oxford: Oxford University Press, 2011.

Raz, Joseph. "Being in the World." In From Normativity to Responsibility, 227-54. Oxford: Oxford University Press, 2011.

Robichaud, Philip, and Jan Willem Wieland, eds. Responsibility: The Epistemic Condition. Oxford: Oxford University Press, 2017.

Rudy-Hiller, Fernando. "The Epistemic Condition for Moral Responsibility." Stanford Encyclopedia of Philosophy (Fall 2018). https://plato.stanford.edu/ archives/fall2018/entries/moral-responsibility-epistemic/.

Sher, George. "Blame and Moral Ignorance." In Robichaud and Wieland, Responsibility, 101-16. Oxford: Oxford University Press, 2017. 
- Who Knew? Responsibility without Awareness. Oxford: Oxford University Press, 2009.

Sliwa, Paulina. "Moral Worth and Moral Knowledge." Philosophy and Phenomenological Research 93, no. 2 (September 2016): 393-418.

_. "On Knowing What's Right and Being Responsible for It." In Robichaud and Wieland, Responsibility, 127-45. Oxford: Oxford University Press, 2017.

Smith, Angela. "Responsibility for Attitudes: Activity and Passivity in Mental Life." Ethics 115, no. 2 (January 2005): 236-71.

Smith, Michael. The Moral Problem. Oxford: Blackwell, 1994. . "Rational Capacities, or: How to Distinguish Recklessness, Weakness, and Compulsion." In Weakness of Will and Practical Irrationality, edited by Sarah Stroud and Christine Tappolet, 17-38. Oxford: Clarendon Press, 2003. Strawson, Peter. "Freedom and Resentment." Proceedings of the British Academy $48(1962): 1-25$.

Talbert, Matthew. "Akrasia, Awareness, and Blameworthiness." In Robichaud and Wieland, Responsibility, 14-63. Oxford: Oxford University Press, 2017.

- "Omission and Attribution Error." In The Ethics and Law of Omissions, edited by Dana Kay Nelkin and Samuel C. Rickless, 17-35. Oxford: Oxford University Press, 2017.

Vargas, Manuel. Building Better Beings: A Theory of Moral Responsibility. Oxford: Oxford University Press, 2013.

Wolf, Susan. Freedom within Reason. Oxford: Oxford University Press, 1990. 